\title{
Kinetic and Mechanistic Study of the Reduction of Chromium(VI) by Lactic Acid
}

\author{
Jinhuan Shan, Fang Wang, Changying Song, and Heye Wang \\ College of Chemistry and Environmental Science, Hebei University, Baoding 071002, Hebei Province, China \\ Correspondence should be addressed to Jinhuan Shan, shanjinhuaner@yahoo.com.cn \\ Received 22 September 2008; Accepted 23 November 2008 \\ Recommended by Rabindranath Mukherjee
}

\begin{abstract}
The kinetics and mechanism of the reduction of chromium(VI) by lactic acid (Lac) in aqueous acidic medium was studied with spectrophotometry in a temperature range of $298.15 \mathrm{~K} \sim 313.15 \mathrm{~K}$. Under the conditions of the pseudo-first order ([Lac $]_{0} \gg$ $\left.[\mathrm{Cr}(\mathrm{VI})]_{0}\right)$, the observed rate constant $\left(k_{\mathrm{obs}}\right)$ increased with the increase in $[\mathrm{Lac}]$ and $\left[\mathrm{H}^{+}\right]$. There is no salt effect. Based on the experimental results, a probable reaction mechanism of oxidation was proposed. The rate equation derived from the mechanism could explain all the experimental phenomena. Activation parameters along with rate constant of the rate-determining step have been evaluated.
\end{abstract}

Copyright (C) 2008 Jinhuan Shan et al. This is an open access article distributed under the Creative Commons Attribution License, which permits unrestricted use, distribution, and reproduction in any medium, provided the original work is properly cited.

\section{Introduction}

Lactic acid is widely used in medications, foods, agriculture, industry, and so forth. It is a fine $\mathrm{pH}$ regulator and has an importance physiological function. Lactic acid can be used to prepare degradable plastics and agroplastic film [1], which can reduce soil and water pollution.

Chromium exists usually in both trivalent and hexavalent forms in aqueous systems. However, these two oxidation states are characterized by markedly different physical/chemical behavior and toxicity. $\mathrm{Cr}$ (III) is readily precipitated or absorbed on a variety of inorganic and organic surfaces at near neutral $\mathrm{pH}[2,3]$. $\mathrm{Cr}$ (III), as an essential trace metal nutrient, also improves lipid profile and glucose tolerance by increasing the level of high density lipoprotein cholesterol and decreasing total serum cholesterol [4]. In contrast, the hexavalent form is of prime concern because of its high toxicity. $\mathrm{Cr}(\mathrm{VI})$ usually occurs as the highly soluble anion. The main sources of chromium pollution are mining, leather tanning, cement industries, electro plating, production of steel and other metal alloys, photographic material, and corrosive paints [5-7]. The hexavalent form of chromium has been demonstrated to be associated with the toxic parameters and classified as human carcinogen and mutagen [8]. Breathing high levels of hexavalent chromium can damage and irritate nose, lungs, stomach, and intestine [9-11]. At present, there have been some researches regarding this type of reaction system [12, 13], while thorough research is essential for understanding its role in the oxidation of some organic compounds. The objectives of this research were to evaluate the kinetics of chromate reduction by lactic acid and investigate their redox mechanisms.

\section{Experimental}

\subsection{Reagents and Apparatus}

All chemicals used were of AR grade, and doubly distilled water was used throughout the work. $\mathrm{NaClO}_{4}$ and $\mathrm{HClO}_{4}$ were used to adjust ionic strength and acidity of the reaction, respectively. The study was performed with a TU-1900 UVVis spectrophotometer fitted with a 501-thermostat $( \pm 0.1 \mathrm{~K}$, Shanghai).

\subsection{Kinetic Measurements and Product Analysis}

Under pseudo-first-order condition ([Lac $\left.]_{0} \gg[\mathrm{Cr}(\mathrm{VI})]_{0}\right)$, the reaction was initiated by mixing the $\mathrm{Cr}(\mathrm{VI})$ to lactic acid solution, and the kinetics was followed at $350 \mathrm{~nm}$ by 


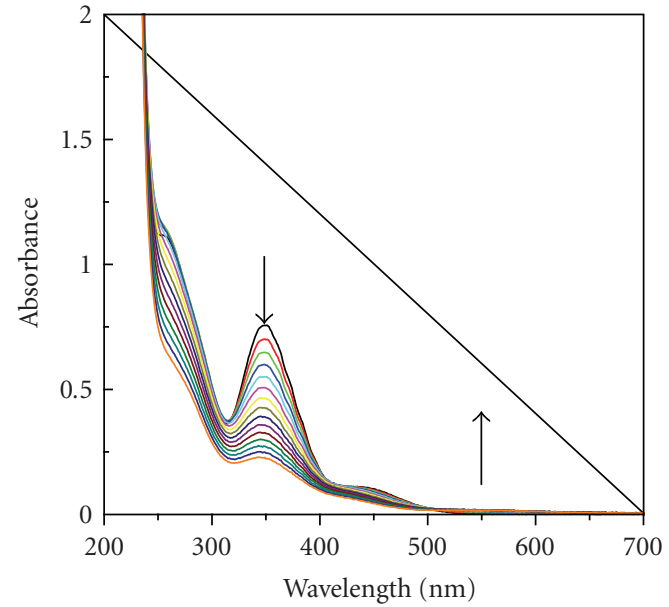

(a)

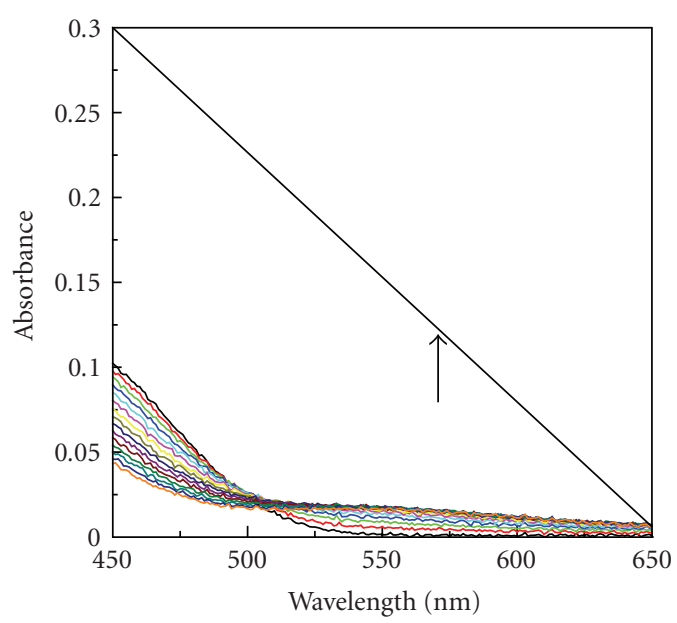

(b)

Figure 1: Spectra changes during the reduction of $\mathrm{Cr}(\mathrm{VI})$ by lactic acid at $298.15 \mathrm{~K}$. $[\mathrm{Cr}(\mathrm{VI})]=2.5 \times 10^{-4} \mathrm{~mol} \cdot \mathrm{L}^{-1},[\mathrm{Lac}]=0.10 \mathrm{~mol} \cdot \mathrm{L}^{-1}$, $\left[\mathrm{HClO}_{4}\right]=0.50 \mathrm{~mol} \cdot \mathrm{L}^{-1},[\mathrm{DMSO}]=0.20 \mathrm{~mol} \cdot \mathrm{L}^{-1}, \triangle t=150$ seconds.

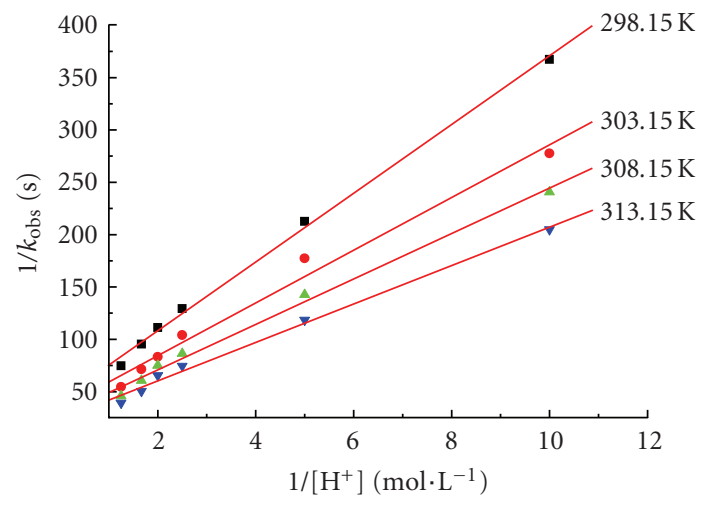

Figure 2: Plots of $1 / k_{\mathrm{obs}}$ versus $1 /\left[\mathrm{H}^{+}\right] .[\mathrm{Cr}(\mathrm{VI})]=2.5 \times$ $10^{-4} \mathrm{~mol} \cdot \mathrm{L}^{-1},[\mathrm{Lac}]=0.50 \mathrm{~mol} \cdot \mathrm{L}^{-1},[\mathrm{DMSO}]=0.20 \mathrm{~mol} \cdot \mathrm{L}^{-1}$, $I=1.0 \mathrm{~mol} \cdot \mathrm{L}^{-1}$.

monitoring decrease in absorbance due to $\mathrm{Cr}(\mathrm{VI})$ (Figure 1). The pseudo-first-order rate constants, $k_{\text {obs }}$, were obtained as in the previous work [14]. The way for product analysis was similar to previous study [15], and the product was identified as the pyruvic acid and $\operatorname{Cr}(\mathrm{III})[16,17]$.

\section{Results and Discussions}

\subsection{Rate Dependence on $\left[\mathrm{H}^{+}\right]$}

It was observed that the rate constants increased by increasing $\left[\mathrm{H}^{+}\right]$, and the plots of $1 / k_{\text {obs }}$ versus $1 /\left[\mathrm{H}^{+}\right]$are linear with positive intercept (Figure 2).

\subsection{Rate Dependence on [Lac]}

The influence of lactic acid on the rate of reaction was studied at different temperatures. The plots of $k_{\text {obs }}$ versus [Lac] are straight lines which pass the grid origin (Figure 3 ).

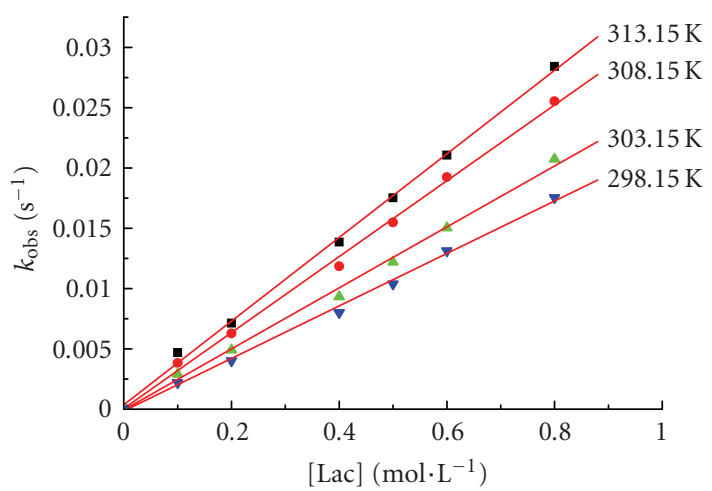

FIGURe 3: Plots of $k_{\mathrm{obs}}$ versus [Lac]. [Cr(VI)] $=2.5 \times 10^{-4} \mathrm{~mol} \cdot \mathrm{L}^{-1}$, $\left[\mathrm{HClO}_{4}\right]=0.50 \mathrm{~mol} \cdot \mathrm{L}^{-1},[\mathrm{DMSO}]=0.20 \mathrm{~mol} \cdot \mathrm{L}^{-1}, I=$ $1.0 \mathrm{~mol} \cdot \mathrm{L}^{-1}$.

\subsection{Effect of Solvent and Ionic Strength $(I)$}

The addition of solvent DMSO accelerates the rate of reduction of $\mathrm{Cr}$ (VI) by lactic acid. When no catalyst or high concentration of acid exists, the oxidation of DMSO is slow so it can be ignored [18-20]. The increase of ionic strength of the reaction almost has no impact on the rate of reaction, indicating that there is no salt effect (Table 1).

\subsection{Mechanism}

The chromic acid also participates in acid-base equilibrium as follows [21]:

$$
\begin{gathered}
\mathrm{H}_{2} \mathrm{CrO}_{4} \rightleftharpoons \mathrm{HCrO}_{4}{ }^{-}+\mathrm{H}^{+}, \quad K_{\mathrm{a} 1}=1.8 \times 10^{-1}, \\
\mathrm{HCrO}_{4}{ }^{-} \rightleftharpoons \mathrm{CrO}_{4}{ }^{2-}+\mathrm{H}^{+}, \quad K_{\mathrm{a} 2}=3.2 \times 10^{-7}, \\
2 \mathrm{HCrO}_{4}{ }^{-} \rightleftharpoons \mathrm{Cr}_{2} \mathrm{O}_{7}{ }^{2-}+\mathrm{H}_{2} \mathrm{O}, \quad K=33 .
\end{gathered}
$$


TABLE 1: Effects of [DMSO] and ionic strength on $k_{\text {obs }}$ at $298.15 \mathrm{~K}$.

\begin{tabular}{lcccccc}
\hline$[\mathrm{DMSO}] / \mathrm{mol} \cdot \mathrm{L}^{-1}$ & 0.050 & 0.10 & 0.20 & 0.30 & 0.40 & 0.50 \\
\hline $10^{3} k_{\mathrm{obs}} / \mathrm{s}^{-1}$ & 4.908 & 5.927 & 6.466 & 7.381 & 7.894 & 8.328 \\
$I / \mathrm{mol} \cdot \mathrm{L}^{-1}$ & 0.60 & 0.80 & 1.0 & 1.1 & 1.2 & - \\
$10^{3} \mathrm{k}_{\mathrm{obs}} / \mathrm{s}^{-1}$ & 5.616 & 5.789 & 5.790 & 5.628 & 6.020 & - \\
\hline
\end{tabular}

$[\mathrm{Cr}(\mathrm{VI})]=2.5 \times 10^{-4} \mathrm{~mol} \cdot \mathrm{L}^{-1},[\mathrm{Lac}]=0.50 \mathrm{~mol} \cdot \mathrm{L}^{-1}$, and $\left[\mathrm{HClO}_{4}\right]=0.50 \mathrm{~mol} \cdot \mathrm{L}^{-1}$.

Hexavalent chromium exists primarily as chromic acid $\left(\mathrm{H}_{2} \mathrm{CrO}_{4}\right)$, hydrogen chromate ion $\left(\mathrm{HCrO}_{4}{ }^{-}\right)$, and chromate ion $\left(\mathrm{CrO}_{4}{ }^{2-}\right)$, depending on the values of $\mathrm{pH}$. In acidic medium of our experiment, dichromate exists predominantly as monomer $\left(\mathrm{HCrO}_{4}{ }^{-}\right)$and chromic acid $\left(\mathrm{H}_{2} \mathrm{CrO}_{4}\right)$, and $\mathrm{H}_{2} \mathrm{CrO}_{4}$ plays a role of active species. Based on the experimental results, we can learn that lactic acid participates in the rate-determined step [22]. From the discussion above, the reaction mechanism was proposed as follows:

$$
\mathrm{HCrO}_{4}^{-}+\mathrm{H}^{+} \stackrel{K_{\mathrm{b}}}{\rightleftharpoons} \mathrm{H}_{2} \mathrm{CrO}_{4},
$$

\section{$\mathrm{H}_{2} \mathrm{CrO}_{4}+\mathrm{CH}_{3} \mathrm{CHOHCOOH}$}

$$
\begin{aligned}
& \stackrel{k}{\longrightarrow} \mathrm{Cr}(\mathrm{IV})+\mathrm{CH}_{3} \mathrm{COCOOH}+\mathrm{H}_{2} \mathrm{O}, \\
& \mathrm{Cr}(\mathrm{VI})+\mathrm{Cr}(\mathrm{IV}) \stackrel{\text { fast }}{\longrightarrow} 2 \mathrm{Cr}(\mathrm{V}),
\end{aligned}
$$

$$
\begin{aligned}
& \mathrm{Cr}(\mathrm{V})+\mathrm{CH}_{3} \mathrm{CHOHCOOH} \\
& \stackrel{\text { fast }}{\longrightarrow} \mathrm{Cr}(\mathrm{III})+\mathrm{CH}_{3} \mathrm{COCOOH}+\mathrm{H}_{2} \mathrm{O} .
\end{aligned}
$$

Here, reaction (3) is the rate-determined step. Based on the mechanism above, the rate law is derived as follow:

$$
\begin{gathered}
-\frac{\mathrm{d}[\mathrm{Cr}(\mathrm{VI})]_{\mathrm{T}}}{\mathrm{dt}}=k\left[\mathrm{H}_{2} \mathrm{CrO}_{4}\right][\mathrm{Lac}], \\
\frac{\mathrm{d}[\mathrm{Cr}(\mathrm{VI})]_{\mathrm{T}}}{\mathrm{dt}}=\frac{k K_{\mathrm{b}}\left[\mathrm{H}^{+}\right]}{1+K_{\mathrm{b}}\left[\mathrm{H}^{+}\right]}[\mathrm{Lac}][\mathrm{Cr}(\mathrm{VI})]_{\mathrm{T}}, \\
k_{\mathrm{obs}}=\frac{k K_{\mathrm{b}}\left[\mathrm{H}^{+}\right]}{1+K_{\mathrm{b}}\left[\mathrm{H}^{+}\right]}[\mathrm{Lac}], \\
K_{\mathrm{b}}=1 / K_{\mathrm{a} 1}, \text { so } k_{\mathrm{obs}}=\frac{k\left[\mathrm{H}^{+}\right]}{K_{\mathrm{a} 1}+\left[\mathrm{H}^{+}\right]}[\mathrm{Lac}], \\
\frac{1}{k_{\mathrm{obs}}}=\frac{K_{\mathrm{a} 1}}{k[\mathrm{Lac}]} \cdot \frac{1}{\left[\mathrm{H}^{+}\right]}+\frac{1}{k[\mathrm{Lac}]} .
\end{gathered}
$$

Reaction (3) shows a redox decomposition with a twoelectron transfer ( $\mathrm{C}-\mathrm{H}$ cleavage), and the redox product is pyruvic acid, which is consistent with the experimental phenomena. From (8) and (10), the plots of $k_{\text {obs }}$ versus [Lac]are straight lines through the grid origin, and the plots of $1 / k_{\text {obs }}$ versus $1 /\left[\mathrm{H}^{+}\right]$are linear with positive intercept. The rate constants of the rate determining step and activation parameters were obtained and presented in Table 2. The effect of solvent on reaction rate is an extremely complicated
TABle 2: The rate constants and activation parameters for the reduction of $\mathrm{Cr}(\mathrm{VI})$ by lactic acid.

\begin{tabular}{lcl}
\hline$T / \mathrm{K}$ & $10^{2} \mathrm{k} / \mathrm{mol}^{-1} \cdot \mathrm{L} \cdot \mathrm{s}^{-1}$ & $\begin{array}{c}\text { Thermodynamic activation } \\
\text { parameters }(298.15 \mathrm{~K})\end{array}$ \\
\hline 298.15 & 4.74 & $E_{\mathrm{a}}=30.98 \mathrm{~kJ} \cdot \mathrm{mol}^{-1}$ \\
303.15 & 5.93 & $\Delta S^{\neq}=-174.6 \mathrm{~J} \cdot \mathrm{K}^{-1} \cdot \mathrm{mol}^{-1}$ \\
308.15 & 7.35 & $\Delta H^{\neq}=28.50 \mathrm{~kJ} \cdot \mathrm{mol}^{-1}$ \\
313.15 & 8.58 & \\
\hline
\end{tabular}

issue. We hold that the formation of $\mathrm{H}_{2} \mathrm{CrO}_{4}$ makes its electron density drop. So, the reaction rate increases with the decreasing of the solvent's polarity [23]. This is consistent with the experimental phenomena.

\section{Conclusion}

The kinetics of the reduction of chromium(VI) by lactic acid in the presence of DMSO has been studied. The active species of $\mathrm{Cr}(\mathrm{VI})$ is understood to be $\mathrm{H}_{2} \mathrm{CrO}_{4}$. Rate constant of the slow step and activation parameters were computed, respectively. The product of $\mathrm{Cr}(\mathrm{VI})$ oxidation of lactic acid is pyruvic acid, which suggested that the cleavage of C$\mathrm{H}$ of lactic acid. Mechanism proposed for the reaction is in conformity with the product, mechanistic, and kinetic studies.

\section{References}

[1] H. Y. Wang, F. Li, S. P. Liang, and X. H. Chen, "Study on synthesis and properties of biodegradable polylactic acid," Chemistry \& Bioengineering, vol. 22, no. 12, pp. 29-31, 2005.

[2] D. C. Schroeder and G. F. Lee, "Potential transformations of chromium in natural waters," Water, Air, \& Soil Pollution, vol. 4, no. 3-4, pp. 355-365, 1975.

[3] R. J. Kieber and G. R. Helz, "Indirect photoreduction of aqueous chromium(VI)," Environmental Science \& Technology, vol. 26, no. 2, pp. 307-312, 1992.

[4] R. A. Anderson, "Chromium as an essential nutrient for humans," Regulatory Toxicology and Pharmacology, vol. 26, no. 1, pp. S35-S41, 1997.

[5] N. K. Chandra Babu, K. Asma, A. Raghupathi, R. Venba, R. Ramesh, and S. Sadulla, "Screening of leather auxiliaries for their role in toxic hexavalent chromium formation in leather-posing potential health hazards to the users," Journal of Cleaner Production, vol. 13, no. 12, pp. 1189-1195, 2005.

[6] M. F. Bergamini, D. P. dos Santos, and M. V. B. Zanoni, "Development of a voltammetric sensor for chromium(VI) 
determination in wastewater sample," Sensors and Actuators B, vol. 123, no. 2, pp. 902-908, 2007.

[7] S. Swarnalatha, T. Srinivasulu, M. Srimurali, and G. Sekaran, "Safe disposal of toxic chrome buffing dust generated from leather industries," Journal of Hazardous Materials, vol. 150, no. 2, pp. 290-299, 2008.

[8] H. Y. Shrivastava, T. Ravikumar, N. Shanmugasundaram, M. Babu, and B. U. Nair, "Cytotoxicity studies of chromium(III) complexes on human dermal fibroblasts," Free Radical Biology \& Medicine, vol. 38, no. 1, pp. 58-69, 2005.

[9] S. A. Katz and H. Salem, "The toxicology of chromium with respect to its chemical speciation: a review," Journal of Applied Toxicology, vol. 13, no. 3, pp. 217-224, 1993.

[10] E. Malkoc, Y. Nuhoglu, and Y. Abali, "Cr(VI) adsorption by waste acorn of Quercus ithaburensis in fixed beds: prediction of breakthrough curves," Chemical Engineering Journal, vol. 119, no. 1, pp. 61-68, 2006.

[11] P. Sanz, J. L. Moline, D. Sole, and J. Corbella, "Nasal septum perforation in chromate-producing industry in Spain," Journal of Occupational Medicine, vol. 31, no. 12, pp. 1013-1014, 1989.

[12] H. Zeng and Z. Lin, "Kinetic study of 2,2' -bipyridyls catalyzed chromic acid oxidation of isopropanol," Chinese Journal of Organic Chemistry, vol. 14, no. 4, pp. 526-531, 1994.

[13] B. L. Hiran, S. L. Chaplot, V. Joshi, and G. Chaturvedi, "Kinetics of the effect of some bidentate amino acid ligands in the oxidation of lactic acid by chromium(VI)1," Kinetics and Catalysis, vol. 43, no. 5, pp. 657-661, 2002.

[14] J.-H. Shan, J. Qian, M.-Z. Gao, S.-G. Shen, and H.-W. Sun, "Kinetics and mechanism of oxidation of $n$-propanolamine by dihydroxydiperiodatonickelate(IV) in alkaline medium," Turkish Journal of Chemistry, vol. 28, no. 1, pp. 9-16, 2004.

[15] T.-S. Shi, J.-T. He, T.-H. Ding, and A.-Z. Wang, "Studies of unusual oxidation states of transition metals III-kinetics and mechanism of oxidation of triethanolamine by diperiodatoargenate(III) ion in aqueous alkaline medium," International Journal of Chemical Kinetics, vol. 23, no. 9, pp. 815-823, 1991.

[16] F. Feigl, Spot Tests in Organic Analysis, Elsevier, New York, NY, USA, 1956.

[17] Z. Khan, Z. A. Rafiquee, and K. Din, "Oxidation of Lmethionine with aqueous chromic acid: a kinetic study," Transition Metal Chemistry, vol. 22, no. 4, pp. 350-355, 1997.

[18] Z. Khan, K. Din, and M. Akram, "Kinetics and mechanism of the reduction of chromium(VI) with dimethyl sulfoxide," Journal of Chemical Research Part S, no. 8, pp. 460-461, 1998.

[19] A. K. Das, S. K. Mondal, D. Kar, and M. Das, "Kinetics and mechanism of picolinic acid promoted chromium(VI) oxidation of dimethyl sulfoxide in the presence and absence of surfactants," Journal of Chemical Research Part S, no. 9, pp. 574-575, 1998.

[20] B. Saha, M. Islam, and A. K. Das, "Kinetics and mechanism of 2,2'-bipyridine catalysed chromium(VI) oxidation of dimethyl sulfoxide in the presence and absence of surfactants," Journal of Chemical Research, vol. 2005, no. 7, pp. 471-474, 2005.

[21] Dalian University of Technology Inorganic Chemistry Teaching and Research Room, Inorganic Chemistry, Higher Education Press, Beijing, China, 2001.

[22] J. J. Jin, Kinetics Principle of Chemical Reaction in Liquid Phase, Shanghai Science and Technology, Shanghai, China, 1984.

[23] X. C. Fu, W. X. Shen, and T. Y. Yao, Physical Chemistry, Advanced Education Press, Beijing, China, 1990. 


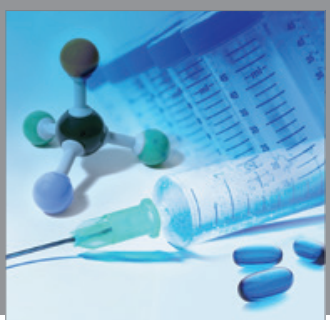

International Journal of

Medicinal Chemistry

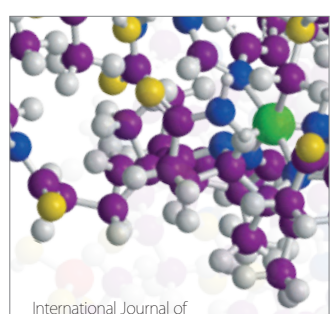

Carbohydrate Chemistry

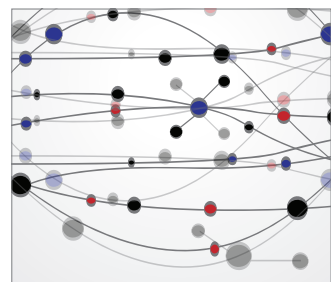

The Scientific World Journal
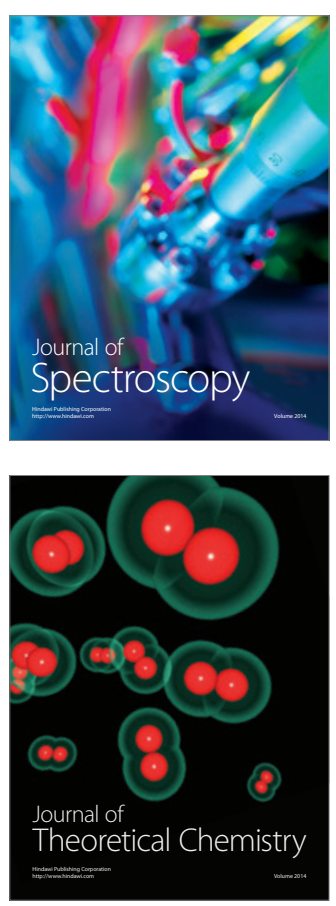
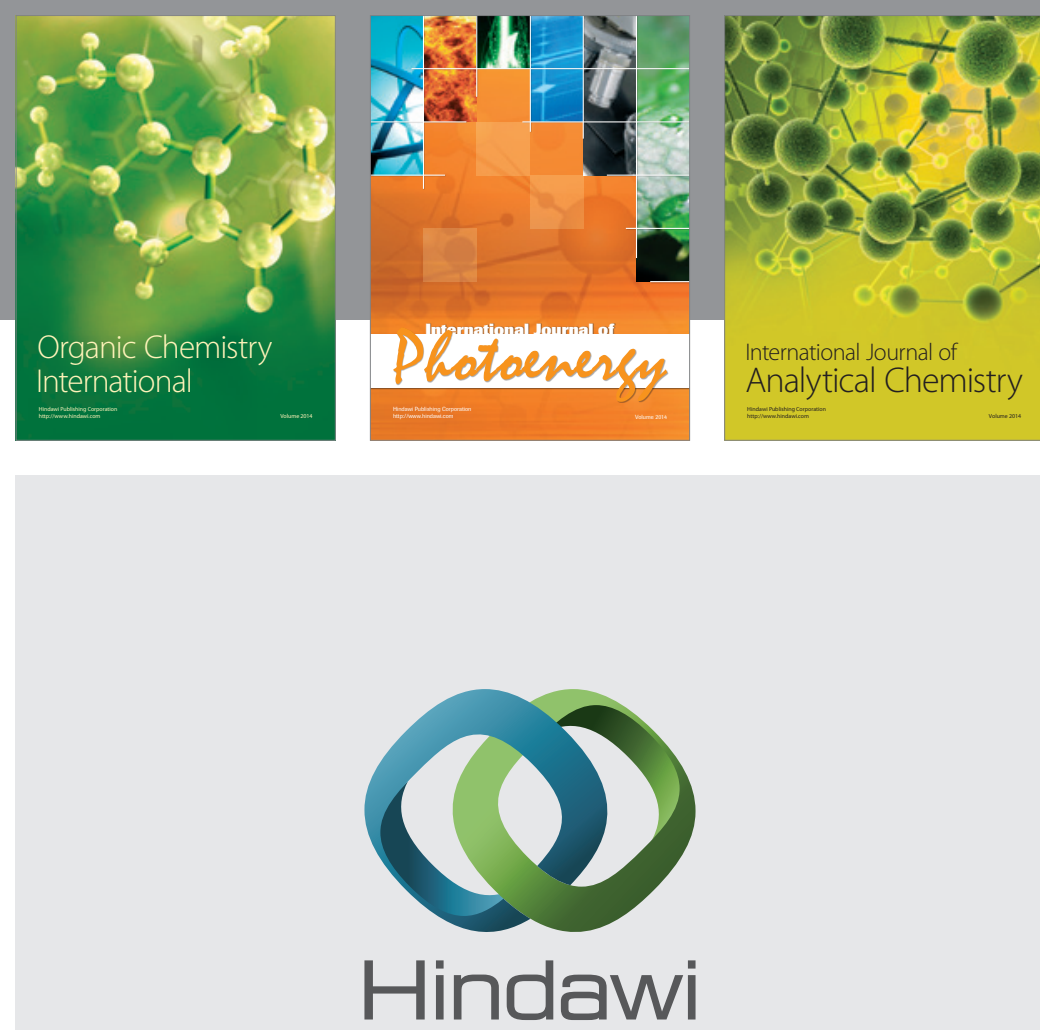

Submit your manuscripts at

http://www.hindawi.com
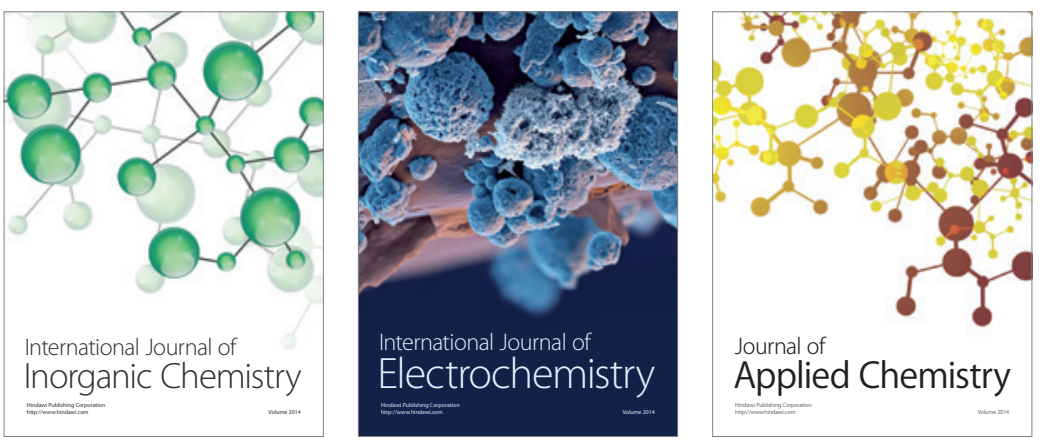

Journal of

Applied Chemistry
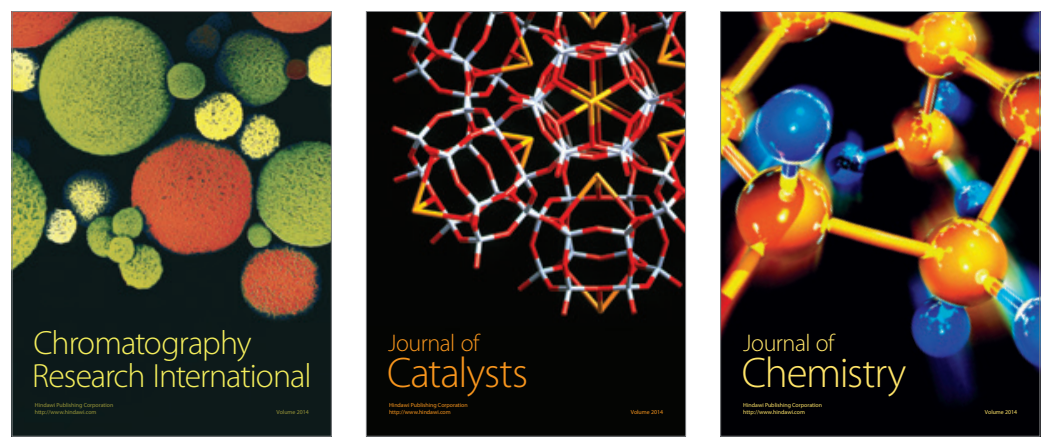
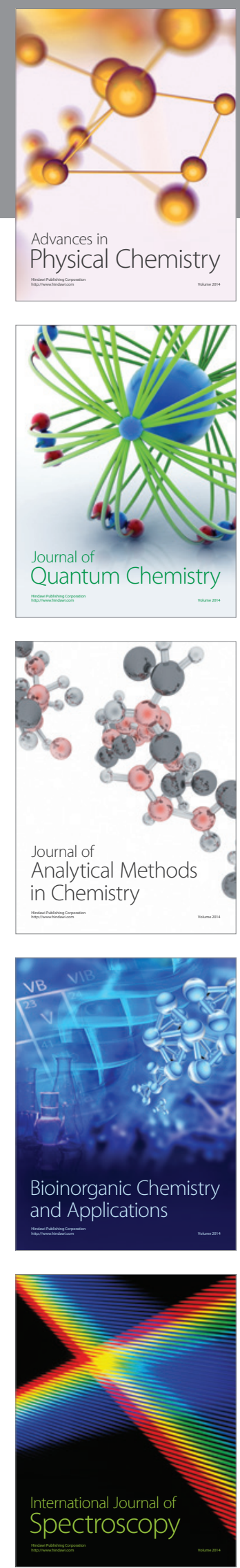